\title{
Study of Some Biochemical Parameters and Fatty Acids Composition in Blood Serum of Men with Nasopharyngeal Carcinoma
}

\author{
Mohamed A. H. Jasim ${ }^{1 *}$, Luma A. M. Bakr ${ }^{2}$ \\ ${ }^{1,2}$ Department of Chemistry, College of Education for Pure Science, Mosul University, Mosul, Iraq \\ E-mail: ${ }^{1 *}$ mohammed.jasim@uomosul.edu.iq, ${ }^{2}$ Lumabaker50@uomosul.edu.iq
}

(Received September 30, 2012; Accepted December 05, 2012; Available online September 01, 2020)

DOI: 10.33899/edusj.2020.166250, ( ) 2020, College of Education for Pure Science, University of Mosul.

This is an open access article under the CC BY 4.0 license (http://creativecommons.org/licenses/by/4.0/).

\begin{abstract}
:
The current study includes a comparison of a number of biochemical variables and the percentage of fatty acids in the blood of patients with Laryngeal and pharyngeal cancer who were diagnosed with the disease, as (25) samples were chosen for patients in the Oncology and Atomic Medicine Hospital in the city of Mosul from various age groups, in addition to (25) samples of healthy people. They did not suffer from any disease and in the same age groups as a control group. Where a number of biochemical variables and the percentage of fatty acids were measured using different techniques and the results of this study showed the presence of many significant differences for the studied variables, which indicates the existence of a significant effect of the studied disease condition on these variables.
\end{abstract}

Keyword : Laryngeal cancer, fatty acids, hemoglobin, white blood cells

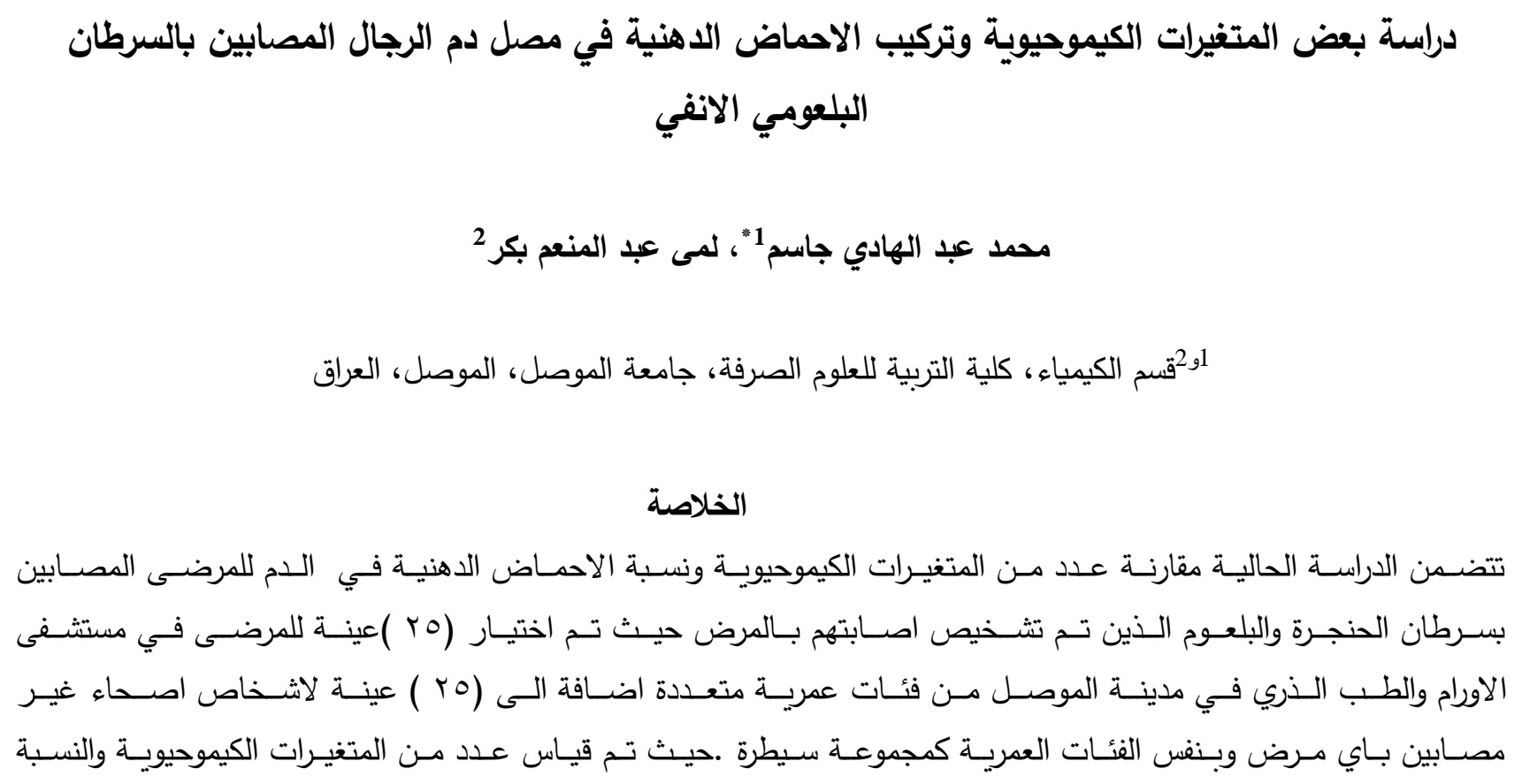




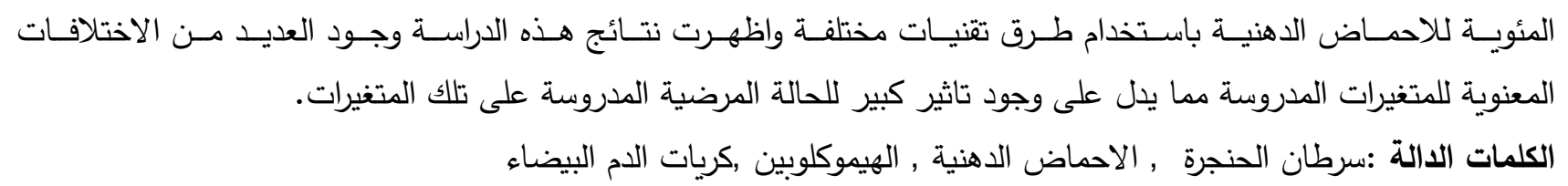

\section{Introduction}

Larynx and pharyngeal cancer occurs when cells in the organs for breathing and swallowing are divided abnormally and quickly, as most types of cancer in this type are concentrated in the area of the vocal cords and then move to the larynx and then all the back parts of the throat (the entire pharynx) are affected and this is The type of cancer is very common in the group of smokers, where the risk factor is very high and the risk factors increase when consuming alcohol. This type of cancer is considered widespread in Asian and African countries and is caused by dietary, genetic and viral factors [1].

This type of cancer is associated with other types of cancer such as oral cancer and then lung cancer and esophageal cancer, as well as this type of cancer may be transmitted to the bladder in some people. This type of cancer of the larynx and pharynx can be treated with the possibility of affecting the speech process [2].

Larynx and pharyngeal cancer, commonly known as nasopharyngeal cancer, is classified as a malignant neoplasm, or cancer, arising from the mucosal epithelium of the nasopharynx, most often within the lateral Larynx and pharyngeal recess or fossa of Rosenmüller [3]. The World Health Organization Classifies Nasopharyngeal Carcinoma in three types. Type1 (I) is squamous cell carcinoma. Type $2 \mathrm{a}$ (II) is keratinizing undifferentiated carcinoma. Type $2 \mathrm{~b}$ (III) is nonkeratinizing undifferentiated carcinoma undifferentiated form is most common, and is most strongly associated with Epstein-Barr virus infection of the cancerous cells [4].

Lymphadenitis is considered one of the causes of laryngeal and pharyngeal cancer, as $40 \%$ of patients suffer from a nodular malignancy in the throat area [5] then this tumor extends to the epiglottis and base of the tongue, especially when patients have a history of smoking where the onset of symptoms appears as a roughness of the voice and hoarseness It is an early symptom due to the increase in the stiffness of the vocal cord, and this leads to the occurrence of great pain in swallowing as well as pain in the ear area [6] which indicates a serious progression of the disease, and many successive examinations must be performed to obtain information on the development of the disease in order to prevent its spread to other parts of the body [7].

\section{Materials and Methods}

\section{Samples collection :}

The blood samples were collected from patients fasting period for (10-12)hours and (5) ml of blood was collected and separated serum from it and then divided in to two parts : $1^{\text {st }}$ part measurement of the following parameters hemoglobin $(\mathrm{Hb})$

, total cholesterol(TC), packed cell volume (PCV), white blood cells( WBC) , platelet using kites[8,9] . the $2^{\mathrm{n}}$ stored at $(-18)^{\circ} \mathrm{c}$ to measurement fatty acids.

2. Extraction and Separation of lipids from serum :

Blood serum is treated with a mixture of methanol and chloroform for the purpose of fat extraction [10], The extracted fats were divided into threeparts cholesterol ester (CE),triglyceride(TG),phospholipids(PL)using thin layer chromatography (TLC)[11] 
3. Transmethylation of fatty acids:

In this study analysis and esterfication of fatty acids by using tri-floro boron $\left(\mathrm{BF}_{3}\right)$ in Methanol(16\%)[11].

4. Measurmeant of percentage of fatty acids:

Measurement of fatty acids was performed by (CGC) Shimadzo 2010,column TR-WAX, length $30 \mathrm{~m}$, in industry center (Syria ).

5-Statistical analysis:

Results were analyzed statistically using $\boldsymbol{t}$-test, $\boldsymbol{P}<0.05$ was considered statistically significant [12].

\section{Results and Dissociation}

\section{1- Biochemical Parameters:}

The results showed that a significant decrease in hemoglobin $(\mathrm{Hb})$ in patients compared to control group as indicated in table (1) this decrease may be due to the formation of tumor blood vessels is caused by anemia, which leads to the formation of cancer cells that resist the process of programmed death of cells, which leads to a lack of oxygen needed for normal cells [13] and the results showed that a significant decrease in (PCV) in patients comparison with control group as show in table (1) the cause of that may be due to directly implicate the necessary blood properties capable of inducing thrombotic diathesis[14] .on the other hand, the results showed that a significant decrease in (W.B.C) may be due to makes it easierto get an infection[15]. the results showed that significant decrease in Platelet as show in table (1) may be due to stabilizing tumor cell arrest in the vasculature or stimulating tumor cell proliferation [16], whereas the results showed that a significant increase in (TC) ) may be due to the action of insulin will be greatly affected by inhibition of the protein lipase enzyme by increasing the formation of the tumor proliferation factor [17].

Table(1): Serum Parameters from patients and control subjects

\begin{tabular}{|l|c|c|}
\hline Parameters & Control 25 & patients (smoking) 25 \\
\hline Hb gm $/ \mathrm{L}$ & $143 \pm 3.9$ & $113 \pm 3.7^{*}$ \\
\hline P.C.V \% & $0.43 \pm 0.015$ & $0.33 \pm 0.011^{*}$ \\
\hline W.B.C $* 10^{9} / \mathrm{L}$ & $7.20 \pm 0.69$ & $4.60 \pm 0.6^{*}$ \\
\hline Platelet $* 10^{9} / \mathrm{L}$ & $197 \pm 13$ & $139 \pm 7.2^{*}$ \\
& & \\
\hline TC $\mathrm{mmol} / \mathrm{L}$ & $180 \pm 40.13$ & $262 \pm 61.71^{*}$ \\
\hline
\end{tabular}


2-Percentage of fatty acids:

The percentage of F.A was measured using (CGC) through comparison with standard sample composed of (12) F.A.

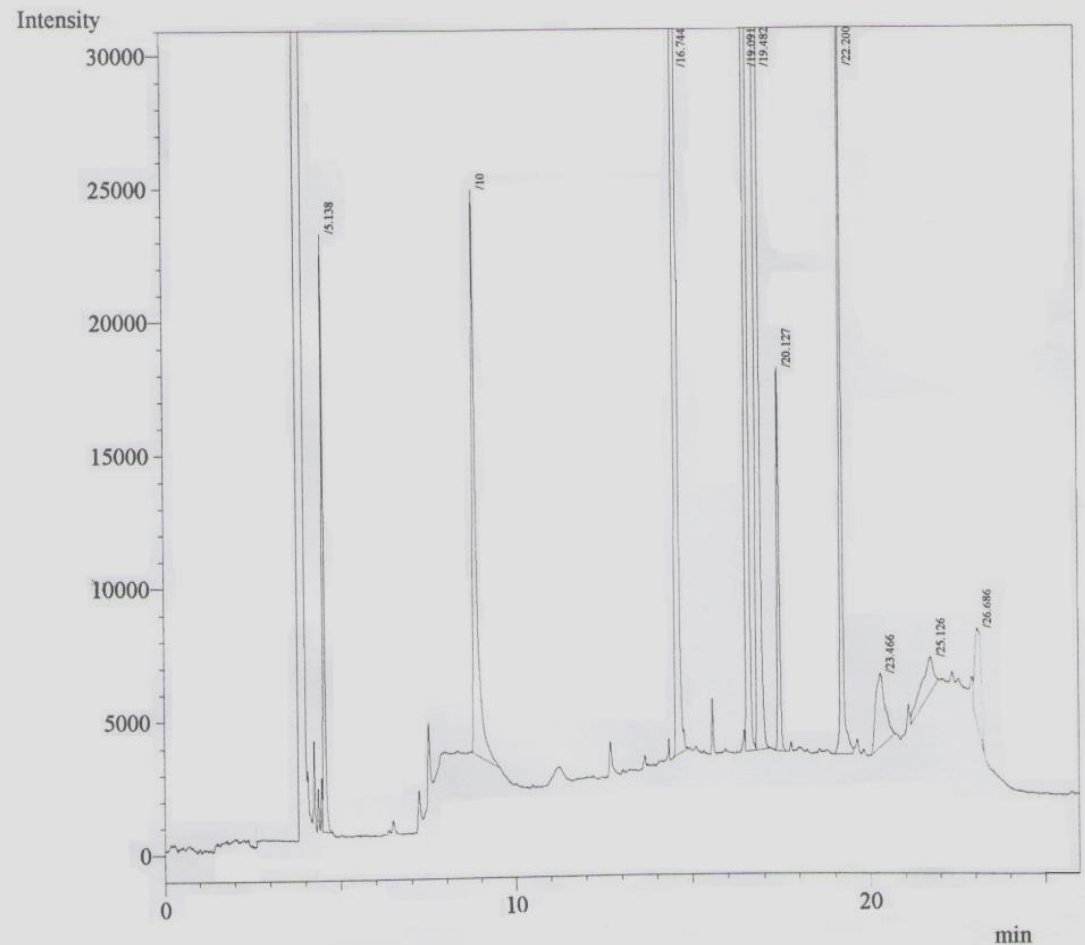

Figure (1):The CGC chart of (12) standard fatty acids 


\section{1- Fatty acids in (CE) part :}

Results showed that a significant increases in percentage of total saturated fatty acids (SFA) in patient in comparison with control group, as show in table (2), this increasing may be due to abnormality in metabolism of fatty acids in patients [18].also a significant decrease in percentage of total monounsaturated fatty acids (MUFA) and a significant increase in percentage of total polyunsaturated fatty acids (PUFA) in this parts, this increasing may be due to hypothesis that the reduction of these metabolites with age may result in a compromised ability to defend against uncontrolled cell growth and inflammation [19].

\section{2- Fatty acids in (TG) part:}

The results showed that a significant increase in percentage of total (SFA) and total (MUFA), on the other hand a significant decrease in percentage of total (PUFA) in patients in compared with that of control , as shown in table (2), this may be due to Suppression of cyclooxygenase and inhibition of prostaglandin E2 synthesis by nonsteroidal antiinflammatory drugs is thought to be the main mechanism [20].

2.3- Fatty acids in (PL) part :

The results showed that a significant increase in percentage of total (SFA), on the other hand a significant increase in percentage of total (MUFA) and (PUFA) in patients in comparison with control group ,as show in table (2), this increasing may be due to The tumor growth suppressing mechanisms of n-3 PUFAs are thought to be due to generation of eicosanoid mediators with biological activity or modulation of signal transduction andgene expression with subsequent induction of apoptosis or modulation of insulin sensitivity [21,22]

Table(2): Percentage of fatty acids in serum patients and control group

\begin{tabular}{|c|c|c|c|c|c|c|}
\hline \multirow{2}{*}{ F.A } & \multicolumn{2}{|c|}{ CE } & \multicolumn{2}{c|}{ PL } & \multicolumn{2}{c|}{ TG } \\
\cline { 2 - 7 } & control & patients & control & Patients & control & patients \\
\hline $\mathrm{n}$ & 25 & 25 & 25 & 25 & 25 & 25 \\
\hline SFA & & & & & & \\
\hline $10: 0$ & $1.3 \pm 0.29$ & $8.80 \pm 0.05$ & $0.00 \pm 0.00$ & $0.75 \pm 0.08$ & $0.10 \pm 0.04$ & $0.3 \pm 0.10$ \\
\hline $12: 0$ & $1.3 \pm 0.31$ & $4.79 \pm 0.22$ & $1.5 \pm 0.03$ & $5.35 \pm 1.50$ & $2.00 \pm 0.30$ & $6.0 \pm 0.15^{*}$ \\
\hline $14: 0$ & $0.34 \pm 0.18$ & $4.22 \pm 0.30$ & $0.38 \pm 0.15$ & $2.95 \pm 0.18^{*}$ & $4.0 \pm 0.65$ & $5.24 \pm 0.38$ \\
\hline $16: 0$ & $21.00 \pm 0.29$ & $24.4 \pm 1.83^{*}$ & $1.74 \pm 0.8$ & $4.52 \pm 1.31^{*}$ & $25.0 \pm 2.60$ & $24.0 \pm 3.34$ \\
\hline $18: 0$ & $1.8 \pm 0.29$ & $5.35 \pm 0.85^{*}$ & $3.50 \pm 0.45$ & $8.75 \pm 1.87$ & $5.25 \pm 1.24$ & $7.25 \pm 0.9^{*}$ \\
\hline Total & $25.75 \pm 3.00$ & $47.56 \pm 3.25^{*}$ & $7.12 \pm 1.43$ & $22.32 \pm 4.94^{*}$ & $36.35 \pm 4.83$ & $42.8 \pm 4.9^{*}$ \\
\hline MUFA & & & & & & \\
\hline $16: 1$ & $1.70 \pm 0.29$ & $2.24 \pm 0.87$ & $2.30 \pm 0.66$ & $8.60 \pm 0.87 *$ & $3.50 \pm 0.35$ & $7.28 \pm 1.2^{*}$ \\
\hline $18: 1$ & $15.0 \pm 1.90$ & $5.33 \pm 0.63^{*}$ & $3.70 \pm 0.58$ & $9.26 \pm 2.11^{*}$ & $20.24 \pm 1.24$ & $18.9 \pm 1.8^{*}$ \\
\hline Total & $16.70 \pm 2.00$ & $7.57 \pm 0.15^{*}$ & $6.00 \pm 1.24$ & $17.86 \pm 2.98^{*}$ & $23.74 \pm 1.59$ & $26.18 \pm 3 . *$ \\
\hline PUFA & & & & & & \\
\hline $18: 2 \mathrm{n}-6$ & $1.03 \pm 0.40$ & $5.31 \pm 0.46^{*}$ & $14.78 \pm 3.2$ & $20.65 \pm 1.65$ & $18.26 \pm 2.77$ & $17.12 \pm 1.9$ \\
\hline $18: 3 \mathrm{n}-3$ & $2.30 \pm 0.39$ & $16.6 \pm 2.31^{*}$ & $2.10 \pm 0.98$ & $8.74 \pm 2.43^{*}$ & $2.85 \pm 0.67$ & $1.80 \pm .55$ \\
\hline $20: 4 \mathrm{n}-6$ & $8.50 \pm 1.29$ & $10.96 \pm 1.83^{*}$ & $8.24 \pm 3.2$ & $17.28 \pm 2.29^{*}$ & $4.85 \pm 0.55$ & $3.24 \pm .76$ \\
\hline $20: 5 \mathrm{n}-3$ & $1.63 \pm 0.13$ & $11.0 \pm 1.88^{*}$ & $2.85 \pm 0.34$ & $8.56 \pm 1.20^{*}$ & $2.90 \pm 0.54$ & $2.68 \pm .21$ \\
\hline $22: 6 \mathrm{n}-3$ & 0.00 & 0.00 & $2.3 \pm 0.50$ & $6.5 \pm 1.54^{*}$ & $6.65 \pm 0.88$ & $2.56 \pm 1.3 *$ \\
\hline Total & $13.43 \pm 7.0$ & $43.87 \pm 6.48^{*}$ & $30.27 \pm 8.2$ & $61.73 \pm 9.11^{*}$ & $35.51 \pm 5.41$ & $27.4 \pm 4.7^{*}$ \\
\hline Values :Mean \pm SD & & $*: \mathrm{P}$ value $<0.05$ & & & \\
\hline
\end{tabular}




\section{Reference}

1- Jemal A, Siegel R, Xu J, Ward E. C . CA Cancer J Clin. ; 60:277-300.(2017)

2- Mourad M, Jetmore T, Jategaonkar. Epidemiological Trends of Head and Neck : A SEER Population Study. J. Oral Maxillofac. Surg. ;75(12):2562-2572.(2019).

3- AJCC Cancer Staging Manual. 7th ed. New York, NY: Springer, pp 41- 56. (2010)

4- Zhang MJ, Mu JW, Chen XR, Zhang X, Feng C. Effect. Medicine (Baltimore). Jun;97(26):(2018).

5- Hay A, Simo R, Hall G, . Eur Arch Otorhinolaryngol.;276(4):1153-1159.(2019).

6- Yamazaki H, Suzuki G, Nakamura S, Yoshida K, Konishi K, Teshima T, Ogawa K. J. Radiat. Res.;58(4):495-508.(2017).

7- Bhattacharyya S, Mandal . Tumour Biol. ;36(8):6029-36(2015).

8- Michael L, Edward P, Larry S. Clinical Chemistry . $5^{\text {th }}$ Williams \&Wilkins. ; pp.288-292.(2005).

9- Tietz N. Text Book of Clinical Biochemistry .W.B. Saunders Com. Philadelphia,USA;135-140.(1986)

10- Ma J. Shahar E. Am.J.Clin. Nutr.;62:564-571.(2005)

11- Naseem A. Fateh D. and Mohammad H. Pak.J.Med.Sci.;23:546-550 . (2007).

12-Leonard T. Kathleen R. Harcourt Brace Jovanovich.;pp490-495. (1979).

13- Jin G., Jing Y, Yun F .Chinese J. of cancer 8.13. (2010).

14-Elusoji S. , Famodu A .,Aigbe A.African J. 12 .1. (2008).

15- Semenza G. Cancer. Hif J. 5.5 (2006).

16- Kenneth V., Dean G., John D. P . cancer and metastasis reviews 11,325-351 ,(1992).

17- Kiran H. , Hardeep K . Indian J. of Clin.Bio.20 ,1,(2005).

18-Mohr G. Kritz D. and Barret E. Pl.Am.J .Epidemiol.,134:78-85.(1991).

19-Shawn A. , Dushmanthi J. ,Gerald F. Human serum derived hydroxyl long chain fatty acid in cancer .Biomed central Ltd (2011).

20-Reza G. , Kiyonori K., Shinji T. Asian J. of cancer 9 ,(2008).

21- Hall MN, Campos H, Li H.Cancer Epidemiol Biomarkers Prev, 16, (2007).314-21. 
22- Theodore M. , Cathee T., Marian L. American J. of Epidemiology 15;173(12):1429-39(2011). 